\title{
Exploring Posttraumatic Growth in Sierra Leone Using Mixed Methods
}

\author{
Silvia Exenberger ${ }^{1}$ (D) Andreas SteidI ${ }^{2} \cdot$ Aruna Kamara $^{3} \cdot$ Alexandra Huber $^{1}$ (D)
}

Accepted: 2 June 2021 / Published online: 19 June 2021

(c) The Author(s) 2021

\begin{abstract}
The Sierra Leonean population has faced severe collective traumata (e.g., civil war, Ebola). Although adversities have a devastating impact on people's lives, there is strong evidence that the struggle with stressful life events can lead to positive changes, which is called posttraumatic growth (PTG). Across many cultures individuals experience PTG. However, the nature of PTG might be influenced by cultural factors. This study aimed to explore PTG in a Sierra Leonean sample using a convergent parallel mixed methods design. The quantitative study investigated the factor structure of the expanded Posttraumatic Growth Inventory (PTGI-X). The qualitative study identified emergent PTG themes. In sum, 360 adults reported on their worst experience and completed the PTGI-X; Additionally, 20 participants took part in in-depth interviews. The original factor structure of the PTGI-X did not apply to this Sierra Leonean sample. A one-factor model including 17 items was supported by confirmatory factor analysis. The qualitative findings revealed PTG dimensions that corresponded to the original ones, which were summarised into the domain "individual growth" (tranquillity and trust, achievement motivation, existential apperception, emphasis on values of life, benevolence). A new domain "collective growth", which reflected societal changes, was found as well. That means, in addition to a personal positive transformation, a social transformation was revealed. The findings indicated that an individualistic measurement such as the PTGI-X falls short to examine growth dimensions in non-Western cultures. A broader definition of PTG might foster the integration of different cultural and collective elements that emerge in response to stressful events.
\end{abstract}

Keywords Posttraumatic growth · Posttraumatic stress disorder - Collective trauma · Stressful life events $\cdot$ Sierra Leone

Silvia Exenberger

silvia.exenberger-vanham@i-med.ac.at

1 Department of Child and Adolescent Psychiatry, Psychotherapy and Psychosomatics, Medical University of Innsbruck, 6020, Anichstraße 35, Innsbruck, Austria

2 Department of Psychology, University of Innsbruck, Innsbruck, Austria

3 Department of Science, Freetown Teachers College, Kossoh Town, Sierra Leone 


\section{Introduction}

The West African country Sierra Leone is a crisis-ridden country. The population of Sierra Leone faced collective traumata (civil war, Ebola), i.e. the entire society showed psychological reactions to these traumatic events (Hirschberger, 2018). Before the civil war, Sierra Leone had been ruled by dictators who enriched themselves through illicit deals with diamonds while neglecting the population's needs for education and other state services (Hanlon, 2005). In 1991, the Revolutionary United Front (RUF) invaded Sierra Leone from Liberia and successfully recruited disenfranchised youth to rise up against the government. Their initial motivations were idealistic and they fought because of their discontent towards the government's corruption and ineffectiveness. However, another motivation of the rebels was gaining access to Sierra Leone's diamond wealth (Bellows \& Miguel, 2009). The 11-year civil war lasted until 2002 and was one of the most violent post-colonial conflicts on the African continent. The RUF rebels targeted people of every ethnic group throughout the country - in this war neither ethnic nor religious divisions played a role (ibid.). In addition to the war atrocities and the devastation of the basic fabric of society, the epidemic virus of Ebola affected the country between 2014 and 2016 (WHO, 2016). Just before the war, Sierra Leone had the second lowest living standard of any country in the world (United Nations, 1993). At present, the living situation has not improved much as Sierra Leone was listed at rank 181 out of 189 countries worldwide on the Human Development Index (HDI) (United Nations Development Programme, 2019).

It is well known that the exposure to highly stressful and traumatic events such as war and terrorism can lead to the development of severe and chronic psychological problems (e.g., Norris, 2002). However, a large number of studies has shown that trauma survivors also experience positive changes in the aftermath of suffering (Tedeschi \& Calhoun, 1995). Tedeschi and Calhoun (1995) coined the term posttraumatic growth (PTG), which is based on the assumption that distress can trigger positive personal transformation (Calhoun \& Tedeschi, 2006). Within the PTG model, a traumatic event is always the starting point of growth and serves as a "seismic" challenge for an individual. Fundamental assumptions about oneself and the world are shattered, and an individual's task consists of reconstructing an assumptive world with the help of supportive others and cognitive processing, such as rumination (Janoff-Bulman, 1992). However, growth takes time to emerge, that means growth measured immediately after the event might rather reflect a cognitive strategy to reduce stress (Park et al., 1996; Tedeschi \& Calhoun, 1995). The development of a quantitative measure in 1996, namely the Posttraumatic Growth Inventory (PTGI, Tedeschi \& Calhoun, 1996), allows capturing experienced growth within five domains: "relating to others", "new possibilities", "personal strength", "spiritual change", and "appreciation of life" (see method section for a description). With regard to the question who engages in growth, Linley and Jospeh (2004) reported in their review on positive change following adversities that women tend to experience higher levels of positive change compared to men, and younger people generally tended to report on more growth, once a given level of developmental maturation is achieved. Park et al. (1996) found that religiosity was positively related to growth as one's religious perspective might provide a framework through which traumata can be appraised. Recently, Tedeschi et al. (2017) expanded the PTGI, which is called the PTGI-X now. Four newly developed spiritual-existential experiences items that are represented in different cultural contexts were added. Tedeschi et al. (2017) confirmed the five-factor structure of the PTGI-X with data of university students of the US, Japan and Turkey. Even though the term "posttraumatic" emphasises that growth occurs in the 
aftermath of a traumatic event, Tedeschi and Calhoun (2004) use the term traumatic event in a broader way (e.g., PTG has been studied with people after romantic relationship breakups, Tashiro \& Frazier, 2003).

The primary purpose of the present study was to explore aspects of posttraumatic growth (PTG) in a Sierra Leonean sample by using a mixed methods design.

\subsection{Culture and PTG}

Even though PTG is a concept that has been established within a Western cultural framework, and consequently reflects a Western individualistic understanding of growth (Splevins et al., 2010), a plethora of scholarly literature shows that PTG also occurs in the aftermath of a wide array of life challenges in different cultures (e.g., Iran/cancer: Heidarzadeh et al., 2017; Iraqi living in Turkey/war-related trauma: Kilic et al., 2015; Israel/Holocaust child survivors: Lev-Wiesel \& Amir, 2003; South Africa/women who experienced childhood sexual abuse: Walker-Williams, van Eeden, and van der Merve, 2012). Therefore, evidence for the universality of the growth construct does exist. Nevertheless, several quantitative studies clearly point out unique features of PTG in specific cultures as the factor structures of the PTGI varied between two (China/cancer: Ho, Chan, and Ho, 2004), three (e.g., former Yugoslavia/former refugees: Powell et al., 2003; Palestine/former political prisoners: Salo et al., 2005; U.S./Latina immigrants: Weiss \& Berger, 2006) and five domains (e.g., Australia: Morris et al., 2005; Germany: Maercker \& Langner, 2001; Netherlands: Jaarsma et al., 2006). Yet other researchers have found that PTG is measured best as a unitary construct (U.K./diverse distressing life events: Joseph et al., 2004; U.S./cardiovascular disease: Sheikh \& Marotta, 2005).

\subsection{Collective Trauma and PTG}

In general, the concept of PTG is universally understood (Splevins et al., 2010). Moreover, research shows that trauma not only is a significant destructive event at the individual level but can also be a catalyst for personal and social transformation at the collective level (Tedeschi, 1999). Some scholars speak about collective growth, which refers to perceived positive changes at a societal level after a collective trauma (ibid.). For example Páez et al. (2007) argued that social sharing and collective coping after the 2004 Madrid bombings reinforced social solidarity and was important for creating a positive emotional atmosphere that led to possible PTG. Positive collective changes after the 9/11 attacks could also be perceived within the U.S. population (Vázquez et al., 2008). In their review about PTG associated with the individual and community impact of terrorist acts, the authors found an "upsurge of patriotism, a greater feeling of cohesion, and stronger faith in any decision that the government might take" (Vázquez et al., 2008, p. 65). Collective PTG takes place through socially shared beliefs of a given group, i.e. at the ideological level whereas individual PTG happens at the cognitive level (Williamson, 2014).

However, Pals and McAdams (2004) claimed that the questionnaire approach of measuring PTG should be complemented with narrative accounts as an individual could experience growth in an area not covered by the five growth dimensions according to Tedeschi and Calhoun (1996). The emergence of new or specified growth aspects in qualitative studies indicated that people respond to stressful events differently, based on their sociocultural context (Hussain \& Bhushan, 2013; Lee, Kim, and Enright, 2017; Shakespeare-Finch \& Copping, 2006). 
The present mixed methods study (data validation-variant, see Fig. 1) aims at exploring various dimensions of PTG experienced by Sierra Leonean civilians as a result of facing intense adversities in life. In general, little is known about PTG among civilians who suffered severe distress in a war zone and during its aftermath (K1lic et al. 2015). According to Hofstede's (2020) country analyses, Sierra Leone is considered a collectivistic society, which manifests itself in the degree of interdependence a society maintains among its members. That means people maintain close long-term commitment to the in-group members, be it one's family, extended family or extended relationships. Society fosters strong relationships where everyone takes responsibility for fellow members of their group (Hofstede, 2020).

The main purpose of the quantitative study was to investigate the factor structure of a Sierra Leonean version of the PTGI-X. Additionally, our objectives were to examine the prevalence of PTG among traumatised and non-traumatised adults, a potential gender difference in the perceived growth, and the relation between PTG and (i) the elapsed time since the traumatic event, (ii) age, (iii) religion. With regard to the reviewed literature, we first hypothesised that the original factor structure of the PTGI-X (Tedeschi et al., 2017) does not apply to a Sierra Leonean population as the original five-factor structure was mainly replicated in cultures similar to the U.S. (Jaarsma et al., 2006; Maercker \& Langner, 2001; Morris et al., 2005). With view to the prevalence of PTG we hypothesised that (1) traumatised participants experience more PTG than non-traumatised participants, based on the fact that major life challenges act as catalysts for growth (Tedeschi \& Calhoun, 2004), and (2) women report more growth than men (Linley \& Joseph, 2004). Concerning the

\begin{tabular}{|c|c|c|}
\hline \multirow[b]{2}{*}{ Research question } & Quantitative sequence & Qualitative sequence \\
\hline & $\begin{array}{l}\text { Prevalence of PTG in a Sierra Leonian } \\
\text { sample }\end{array}$ & $\begin{array}{l}\text { PTG dimensions beyond the PTGI-X } \\
\text { (Tedeschi et al. 2017) }\end{array}$ \\
\hline \multirow[t]{3}{*}{ Data collection } & & $\begin{array}{l}\qquad \downarrow \\
\text { Development of open-ended questions for } \\
\text { a semi-structured interview guide }\end{array}$ \\
\hline & $\downarrow$ & $\downarrow$ \\
\hline & $\begin{array}{l}\text { Revised version of thePosttraumatic } \\
\text { Groth Inventory (PTGI-X, Tedeschi et } \\
\text { al., 2017) \& socio-demographic questions }\end{array}$ & $\begin{array}{l}\text { Open-ended questions regarding to the } \\
\text { traumatic event } \& \text { possible perceived } \\
\text { growth or changes }\end{array}$ \\
\hline \multirow[b]{2}{*}{ Analysis } & $\downarrow$ & $\downarrow$ \\
\hline & $\begin{array}{l}\text { SPSS: analysis of quantitative data } \\
\text { (descriptive statistics) } \\
\text { AMOS: confirmatory factor analysis } \\
\text { (CFA) to examine the goodness-of-fit of } \\
\text { the five-factor structure of the PTGI-X }\end{array}$ & $\begin{array}{l}\text { Qualitative in-depth analysis using } \\
\text { Thematic Analysis (Braun \& Clarke, } \\
\text { 2006) }\end{array}$ \\
\hline \multirow[t]{2}{*}{$\begin{array}{l}\text { Merge the two sets of } \\
\text { data }\end{array}$} & \multicolumn{2}{|c|}{$\begin{array}{l}\text { Identification of themes represented in both data sets, and represented } \\
\text { exclusively in the qualitative data set } \rightarrow \text { comparing, contrasting and/or } \\
\text { synthesising results }\end{array}$} \\
\hline & \multicolumn{2}{|c|}{$\downarrow$} \\
\hline $\begin{array}{l}\text { Interpretation of merged } \\
\text { results }\end{array}$ & $\begin{array}{l}-\quad \text { Summary and } \\
\text { Discussion about to what extent } \\
\text { diverge, relate to each other, an }\end{array}$ & $\begin{array}{l}\text { erpretation of the results } \\
\text { sults from the two types of data converge, } \\
\text { or produce a more complete understanding }\end{array}$ \\
\hline
\end{tabular}

Fig. 1 Flowchart of the convergent parallel design (data-validation variant) adapted from Creswell and Plano Clark (2011) 
correlates of PTG our hypotheses were that (1) time elapsed since the occurrence of trauma is positively related to PTG (Park et al., 1996; Tedeschi \& Calhoun, 1995), (2) younger adults experience higher levels of growth than older ones (Linley \& Joseph, 2004), and (3) religion is positively associated with PTG (Park et al., 1996).

The qualitative data provided emergent themes to validate the quantitative survey findings, and explored the experience or non-experience of PTG in depth. With this mixed methods approach we want to merge quantitative and qualitative data to outline PTG in Sierra Leone.

\section{Method}

\subsection{Research design}

Through a convergent parallel mixed methods design, qualitative and quantitative data were collected parallel, analysed separately and then merged (see Fig. 1).

\subsection{Participants and Procedure}

In January and February 2018, we recruited a non-clinical sample of 360 adults (190 men, 158 women and 12 participants without information on their sex) throughout the settlement of Calaba Town in Eastern Freetown, in various Colleges (e.g., Freetown Teachers College) and the University of Sierra Leone (FOURAH BAY). Students and lecturers of various departments (e.g., arts, sociology and social work, business, biology, chemistry, education) participated. Calaba Town is a melting pot of people originating from all different tribes in Sierra Leone, a fact, which is also true of the Freetown Teachers College. Inclusion criteria were a minimum age of 18, proficiency in the English language (given that Krio been a Pidgin language and most spoken language around Freetown), and self-identification as Sierra Leonean from a cultural perspective. Out of these 360 participants, 20 participants who met the inclusion criteria (focusing on good abilities in spoken English), and who were directly approached during the quantitative study were randomly recruited to take part in the qualitative inquiry. The participants' mean age was 29.92 years, the mean age at the reported critical event was 20.78 , the elapsed time since then was an average of 9.26 years. Most of the participants were either Muslims or Christians. Irrespective of the participants' religious affiliation about $90 \%$ stated that they were active believers. The analysis of the critical event revealed that more than half of the participants described a traumatic event according to DSM-V (Criterion A for PTSD) (American Psychiatric Association, 2013), and the remaining participants reported on a critical life event. Details of socio-demographic data are shown in Table 1.

Participants gave their oral or written consent before participation. Participation was voluntary and anonymous and the participants could resign from participation at any time. In case of uncertainties concerning the completion of the questionnaire, the participants could request assistance. Individual interviews were conducted face-to-face, audio-recorded and transcribed verbatim. Participants had the possibility to contact a psychological professional for consultancy in case the study participation triggered something negative. We followed APA ethical standards in the conduct of the entire study (American Psychological Association, 2017). All procedures performed in studies involving human participants were in accordance with the ethical standards of the institutional and/or national research 
Table 1 Socio-demographic data

\begin{tabular}{lll}
\hline & $n$ & $(\%)$ \\
\hline Sex & & \\
Female & 158 & $43,9 \%$ \\
Male & 190 & $52,8 \%$ \\
No information & 12 & $3,3 \%$ \\
Religion & & \\
Muslim & 227 & $63,1 \%$ \\
Christian & 127 & $35,8 \%$ \\
Hare Krishna & 1 & $0,3 \%$ \\
No information & 5 & $1,4 \%$ \\
Being a believer & & \\
Active believer & 332 & $92,2 \%$ \\
No active believer & 17 & $4,7 \%$ \\
No information & 11 & $3,1 \%$ \\
Trauma vs. stressful event & & \\
Traumatic event & 212 & $58,9 \%$ \\
Stressful event & 148 & $41,1 \%$ \\
& mean & $(\mathrm{SD} ;$ range) \\
Age & 29,92 & $(11,67 ; 18-82)$ \\
Age at the stressful event (years) & 20,72 & $(10,41)$ \\
Elapsed time since the event (years) & 9,26 & $(8,49)$ \\
\hline & & \\
& & \\
& &
\end{tabular}

committee and with the 1964 Helsinki declaration and its later amendments or comparable ethical standards. Due to the nature of the study, which neither involved patients nor required medical treatment or other medical procedures, no approval of this study by the Austrian ethics committee was needed ("Bundesgesetz über die Organisation der Universitäten und ihre Studien (Universitätsgesetz 2002-UG)," 2002/amended 2018; "Hospitals and Health Resorts Act (Bundesgesetz über Krankenanstalten und KuranstaltenKAKuG)," 1957/amended 2016). In Sierra Leone, the ethic committee of the Freetown Teachers College approved the study.

\subsection{Qualitative and Quantitative Study}

All participants filled in the PTGI-X and the short questionnaire on demographic characteristics; 20 participants (out of 360) were part of both, the qualitative (in-depth interviews) and the quantitative inquiry. Of the 20 interviewees, 15 participants were traumatised and 5 participants were non-traumatised.

\subsection{Materials}

\subsubsection{Demographic Characteristics}

Participants reported their age, age at the time of the experienced adversity, gender, and their religious affiliation. 


\subsubsection{Problem-centred Interview (Witzel, 2000)}

A semi-structured guided interview was used to gather the participants' $(N=20)$ narratives. Firstly, they were asked to describe their worst experience ever in detail. Secondly, they were requested to characterise their perceived changes generally and their positive changes specifically (in case they had experienced any). If necessary, questions for ease of reference were asked.

\subsubsection{Posttraumatic Growth Inventory (PTGI-X, Tedeschi et al., 2017)}

The questionnaire starts with an indication or brief description of the participants' worst experience ever. It consists of 25 items to be answered on a 6-point Likert scale, with values ranging from " 0 " meaning I did not experience a change as a result of my crisis to " 5 " meaning I experienced this change to a very great degree as a result of my crisis (scale sum scores 0 to 125). The five PTG domains are (1) relating to others (7 items): having a greater connection to other people; (2) new possibilities (5 items): discovering new paths in life; (3) personal strength (4 items): people became aware of their own vulnerability and yet they were much stronger than they had thought; (4) spiritual and existential change (6 items): diversity of perspectives on spiritual-existential experiences; and (5) appreciation of life (3 items): people changed their priorities in life. The instructions to the Sierra Leonean version of the PTGI-X (PTGI-X-SL) were identical to the original PTGI-X.

The PTGI-X was found to have satisfactory reliability for the total score across three samples: 0.97 for the United States, 0.96 for Turkey, and 0.95 for Japan (Tedeschi et al., 2017).

\subsection{Data Analysis}

\subsubsection{Quantitative Study}

We used confirmatory factor analysis (CFA) to examine the goodness-of-fit of the five-factor structure of the PTGI-X proposed by Tedeschi et al. (2017). As this five-factor-solution did not provide good fit to the data (see Table 3), a further principal component analysis (PCA) with varimax rotation was conducted to investigate the underlying factor structure of the Sierra Leonean version of the questionnaire using SPSS version 24 (IBM, 2016). CFA was subsequently used to confirm possible factor structures as suggested by the PCA results and possible models were tested by using Analysis of Moment Structures (AMOS, Arbuckle, 2014, Version 23). The maximum-likelihood estimation (MLE) method was used to test the covariance matrix to determine how well the model fitted the data. Apart from standard $\chi^{2}$ test with its inherent $p$-value and degrees of freedom (df), the following fit indices are reported for maximum-likelihood-based calculations: Root-Mean-Square-Error of Approximation (RMSEA, cut-off value close to 0.06), Comparative Fit Index (CFI), and Tucker-Lewis-Index (TLI; both, cut-off $>0.90$ ). The quoted cut-offs are according to $\mathrm{Hu}$ and Bentler (1998, 1999).

For comparing data of women and men as well as traumatised and non-traumatised participants, paired t-tests were used with an alpha level of 0.05. Pearson's correlation coefficients were calculated for the total scores of the PTGI-X Sierra Leone and descriptive factors associated with the potential trauma. 
Table 2 Description of the trauma or stressful event comparing women and men $\left(N=348^{*}\right)$, and total $(N=360)$

\begin{tabular}{llll}
\hline & \multicolumn{2}{l}{ Sierra Leonean sample } \\
\cline { 2 - 4 } & Women $(n=158)$ & Men $(n=190)$ & Total $(n=360)$ \\
& $N(\%) ;$ trauma & $N(\%) ;$ trauma & $N(\%)$ \\
\hline Death (e.g., sudden death of a loved one) & $37(23,4 \%)$ & $59(31,1 \%)$ & $100(27,8 \%)$ \\
Civil war & $25(15,8 \%)$ & $39(20,5 \%)$ & $64(17,8 \%)$ \\
Relational issues (e.g., family of origin, relation- & $24(15,2 \%)$ & $21(11,1 \%)$ & $46(11,9 \%)$ \\
$\quad$ ships) & $17(10,8 \%)$ & $26(13,7 \%)$ & $43(9,0 \%)$ \\
Ebola & $15(9,5 \%)$ & $15(7,9 \%)$ & $31(8,6 \%)$ \\
Work and educational issues & $13(8,2 \%)$ & $10(5,3 \%)$ & $24(6,7 \%)$ \\
Accidents & $11(7 \%)$ & $6(3,2 \% 9$ & $19(5,3 \%)$ \\
Physical and mental health & $8(5,1 \%)$ & $6(3,2 \%)$ & $17(4,7 \%)$ \\
Not clearly specified & $5(3,2 \%)$ & $6(3,2 \%)$ & $11(3,1 \%)$ \\
Mudslide, flooding & $3(1,9 \%)$ & - & $3(0,8 \%)$ \\
Rape & - & $2(1,1 \%)$ & $2(0,6 \%)$ \\
Imprisonment & & & \\
\hline
\end{tabular}

*There is no information about sex for 12 participants

\subsubsection{Qualitative Study}

Data were analysed with the software for qualitative data analyses MAXQDA 2018 using Thematic Analysis (TA, Braun \& Clarke, 2006). TA provides a rich thematic description of the entire data set, so that one gets a sense of the predominant themes. That means, TA is particularly a useful method when investigating an under-researched area with participants whose views on the topic are unknown (Braun \& Clarke, 2006). We (the first and the second author) followed the six phases of TA. All steps of analysis were conducted simultaneously but independently from each other: (1) For generating initial ideas about the data we became familiar with the text by reading and re-reading the texts. (2) Then, we used an inductive approach to extrapolate the main characteristics of the most stressful events in the participants' lives. Finally, we rated whether these characteristics were traumatic experiences or not, according to DSM-V. We focused on possible phenomena after having experienced a stressful event, i.e. we systematically coded the sequences referring to descriptions of phenomena experienced after adversities. In the next step we developed codes, and (3) similar codes were grouped together to form themes. (4) These themes were finally grouped and regrouped to review the themes. (5) At this point we (the first and the second author) compared the results of our analysis. In addition, the second author, who stayed for several months in Sierra Leone discussed the final analysis with the third author from Sierra Leone to ensure an understanding of culture-specific findings and the meaning of the findings. Inconsistencies in identified themes and new emerging components of PTG were discussed until consensus was reached. (6) Consequently, we identified higher order domains. To sum up, we developed codes, which explicate the range of themes. Themes were then clustered into higher order domains. 


\section{Results}

\subsection{Quantitative Study}

\subsubsection{Nature of Event}

A broad range of traumatic or stressful life events were covered and are listed in descending order for women and men separately and as a total sample in Table 2.

\subsubsection{The Five-Factor Structure of the Original PTGI-X}

CFA results showed that this model did not fit our data (see Table 3). Thus, the original factor structure of the PTGI-X could not be applied to a Sierra Leonean population who were confronted with stressful or traumatising events.

Model examination Then, corresponding to the development of the original version, a PCA with varimax rotation was conducted on the 25 items of the PTGI-X. The data met prerequisites for PCA (Kaiser-Meyer-Olkin $=0.86$, Bartlett's test of sphericity $\chi^{2}$ $(300)=2293.77, p<0.001)$. Although loadings according to the five original factors had values above 0.4 , the rotated component matrix revealed that the factors contained different items compared to the original growth dimensions according to Tedeschi et al. (2017). The factors were hardly interpretable and therefore, we tried to explore better fitting structures based on theoretical and statistical assumptions.

To identify the factor structure of the Sierra Leonean version, we followed in a first step the suggestion of the explorative PCA with varimax rotation revealing six components with an eigenvalue greater than one (Kaiser, 1960). However, two of them comprised only two items whereas a minimum of three items per factor is required to test the model fit (Buehner, 2006). In a next step, a parallel analysis according to Horn (O'Connor, 2000) for deciding on a number of factors to keep in the PCA was conducted. The results of the parallel analysis barely indicated two factors. The first factor had an eigenvalue of 6.33 and the second factor of 1.96 , with the remaining values below the point of intersection (1.35 to 0.32 ). The two-dimensional structure with the original 25 items did not show a satisfying model fit with one considered modification index (see Table 3). Satisfying model fit could only be reached when item loadings $\leq 0.4$, and in a further step $\leq 0.5$ (MacCallum et al., 1999), were deleted (15 items remained, see Table 3 ). However, the two factors remained very high correlated with either 25 or 15 items ( $r=0.71$ and $r=0.78$ respectively). Furthermore, they were difficult to interpret. Therefore we decided to create a uni-dimensional structure following factor 1 with an eigenvalue above 6 representing PTG. The one-factor model containing

Table 3 Goodness-of-fit indices for different factor models

\begin{tabular}{lllllll}
\hline Model & $\chi^{2}(\mathrm{df})$ & $p$ & CFI & TLI & RMSEA & CMIN/df \\
\hline 5-factor (25 items) & $733.589(269)$ & 0.000 & 0.774 & 0.748 & 0.069 & 2.727 \\
2-factor (25 items) & $646.880(275)$ & 0.000 & 0.819 & 0.802 & 0.061 & 2.352 \\
2-factor (15 items) & $191.962(90)$ & 0.000 & 0.917 & 0.904 & 0.056 & 2.133 \\
1-factor (25 items) & $706.578(272)$ & 0.000 & 0.788 & 0.767 & 0.067 & 2.598 \\
1-factor (17 items) & $234.824(118)$ & 0.000 & 0.915 & 0.902 & 0.053 & 1.990 \\
\hline
\end{tabular}


the original 25 items again did not reach a satisfying model fit, although four modification indices were considered (see Table 3). Satisfying model fit was reached when item loadings $\leq 0.4$ were deleted ( 17 items remained see Table 3 ) and four error terms were allowed to correlate. The error terms (e2-->e13: 0.23; e3-->e7: 0.25; e12-->e13: 0.21 ; e24-->e25: 0.29) can be explained by their former belonging to the same scale of the original 5-factor model or similar meaning. Therefore, these model modifications were taken into account as all items load on the new 'PTG' factor sufficiently and are not logically causally, but merely statistically correlated (Brown, 2015). The final onefactor solution explained $31.21 \%$ of variance in total. The examination of the fit-indices revealed that the two- and the one-factor model had CFI and TLI values above the cutoff of $>0.90$, and RMSEA was clearly below the suggested value of 0.06 . The decision for the uni-dimensional structure is based on the following: (1) one factor reflects the Sierra Leonean diversity of their interpretation of growth best, (2) the two-factor solution with a very high correlation between them seems to be artificial, and (3) the better statistical values of: CMIN/df, and RMSEA (see Table 3).

Table 4 shows the 25 items of the PTGI-X and highlights the items of the two-factor model with 15 items and the final one-factor model with 17 items.

Table 4 Items on the PTGI-X

Item

1. I changed my priorities about what is important in life. (AL)

2. I have a greater appreciation for the value of my own life. (AL)

3. I developed new interests. (NP)

4. I have a greater feeling of self-reliance. (PS)

5. I have a better understanding of spiritual matters. (SEC)

6. I more clearly see that I can count on people in times of trouble. (RO)

7. I established a new path for my life. (NP)

8. I have a greater sense of closeness with others. (RO)

9. I am more willing to express my emotions. (RO)

10. I know better that I can handle difficulties. (PS)

11. I am able to do better things with my life. (NP)

12. I am better able to accept the way things work out. (PS)

13. I can better appreciate each day. (AL)

14. New opportunities are available which wouldn't have been otherwise. (NP)

15. I have more compassion for others. (RO)

16. I put more effort into my relationships. (RO)

17. I am more likely to try to change things, which need changing. (NP)

18. I have a stronger religious faith. (SEC)

19. I discovered that I'm stronger than I thought I was. (PS)

20. I learned a great deal about how wonderful people are. (RO)

21. I better accept needing others. (RO)

22. I have a greater sense of harmony with the world. (SEC)

23. I feel more connected with all of existence. (SEC)

24. I feel better able to face questions about life and death. (SEC)

25. I have greater clarity about life's meaning. (SEC)

All 25 items comprised the five-factor model according to Tedeschi et al. (2017). Bold signifies the items used in the two-factor model and grey signifies the uni-dimensional structure. We have the permission from the scale developers to include the items in this table

Relating to others (RO), New Possibilities (NP), Personal Strength (PS), Spiritual and Existential Change (SEC), Appreciation of Life (AL) 


\subsubsection{Internal Consistency}

The Cronbach's $\alpha$ coefficient of the total PTGI-X-SL with 17 items was 0.86 .

\subsubsection{Prevalence}

PTGI-X-SL total sum score ranged from 0 to 85 (maximum score: 85 ). Half of the participants had total sum scores of 54 or higher $(50.0 \%)$, which reflects perceived change $(M=54.89, S D=15.37)$. The $t$-test revealed there were no significant differences in experienced growth between men $(M=55.16, S D=14.43)$ and women $(M=54.51, S D=16.42$, $t(346)=0.397$, ns, $d<0.1)$. There was not found any difference in experienced growth between participants reporting a traumatic event $(M=55.42, S D=16.03)$ and reporting no traumatic event $(M=54.14, S D=14.39, t(358)=-0.773$, ns, $d<0.1)$ either.

\subsubsection{Correlations Between PTGI-X-SL Total Score and Socio-demographic Factors}

No correlations were detected between the total PTGI-X-SL score and the socio-demographic factors of age, sex, time elapsed since the trauma, religiousness, and the worst experienced event estimated as a traumatic event.

\subsection{Qualitative Study}

The analysis of the qualitative data resulted in two different domains: "individual growth" and "collective growth". The first domain consisted of five PTG themes or PTG dimensions in terms of Tedeschi et al. (2017) and fifteen codes, and the second domain comprised one PTG theme with two inherent codes (see Table 5). In the following, we will give an overview of each domain and its identified themes as well as codes.

Table 5 Domains, themes, and codes of PTG in a Sierra Leonean sample

\begin{tabular}{|c|c|c|}
\hline Domains & Themes & Codes \\
\hline \multirow[t]{5}{*}{ Individual growth } & Tranquillity and trust & $\begin{array}{l}\text { Acceptance of destiny } \\
\text { Competence } \\
\text { Optimism } \\
\text { Peace of mind }\end{array}$ \\
\hline & Achievement motivation & $\begin{array}{l}\text { Intensifying previous actions } \\
\text { Motivation for new things }\end{array}$ \\
\hline & Existential apperception & $\begin{array}{l}\text { Contemplating on life } \\
\text { Conscious reflection on traumatic event } \\
\text { Enhanced faith } \\
\text { Having confidence in God }\end{array}$ \\
\hline & Emphasising values of life & $\begin{array}{l}\text { Appreciation of ideals } \\
\text { Appreciation of fellow humans and family } \\
\text { Appreciation of present situation and life itself }\end{array}$ \\
\hline & Benevolence & $\begin{array}{l}\text { Caring actions for others } \\
\text { Encouraging others due to experience }\end{array}$ \\
\hline Collective growth & Social transformation & $\begin{array}{l}\text { Collective development } \\
\text { System development }\end{array}$ \\
\hline
\end{tabular}




\subsubsection{Individual Growth}

This domain focuses on growth experienced on an individual level and the identified themes are similar to the original growth dimensions according to Tedeschi et al. (2017). A salient characteristic of this domain is the reliance on and the confidence in God or Allah. With a few exceptions, the importance of God or Allah is emphasised during all interviews. In brackets we indicate how many traumatised persons and how many non-traumatised persons-expressed as a percentage-mentioned this theme.

Tranquillity and trust (87\%/80\%). The majority of participants reported about their present tranquil way of living and their outlook on the world regarding the past, the present and the future. In addition, they pointed out their trust and confidence in their own abilities, i.e. they had become aware of their own competence and strength. One interview partner who was accused by the military of encouraging rebels during the war (which is like a sentence to death) stated: "If I can overcome such difficulties I have nothing to fear. Yes, I have nothing to fear. I believe that." To reach a peaceful mindset, participants put a focus on forgiving and forgetting of past events and persons involved in them. An interviewee who was driven out of the house because of big troubles with her family-in-law stated: "And never you say I will not forgive and I forget. Forgive and forget and then you move on. What if you forgive and don't forget, it will always come into your mind." Other participants reported on a positive way of looking at how things worked out in life, other participants even referred to a positive outlook on the future.

Achievement Motivation (47\%/20\%). About half of the interview partners described a change of motivation and behaviour resulting from the traumatic or stressful events they had faced. The interviewees differentiated between motivation for continuing actions, which they already had started before the traumatic event and the motivation for engaging in new actions and/or challenges after the trauma. A witness of the atrocities of war, who had got a teacher certificate before the war, mentioned: "Then just after the war, in 2001, I worked a little to upgrade myself a little again, looking for various courses as well." Another participant whose husband was attacked by the rebels in front of her eyes found a way out of "being down" through education: "Indeed! The war really motivated me. Because by then I was down there... I was down down below. But when I came down I have changed my life. And now I am doing something here."

Existential Apperception (67\%/100\%). Given the fact that the great majority of the interviewees emphasised the continuous confidence and trust in God as a constantly present relation, this specific theme is created to cover explicitly the importance of the integration of God in their lives. For example, a bereaved father whose relationship in addition to the loss of his child fell apart during the Ebola crises looked back on his life: "You have to care the faith in God and whatsoever difficulties come in your way... there is a success behind it. If actually you focus to God, focus in what you want to do ...". Some participants even commented on having a stronger faith in God after the traumatic experience, and many of them referred to their reliance on God and God's will when speaking about the traumatic experience: "So those who died because of that crisis it was a destiny that God has marked for them, that they were going to die. Those who live by now, it is a destiny that we are going to live...".

Emphasising values of life $(67 \% / 60 \%)$. In general, the participating adults reported an increased appreciation of ideals. A teacher, who witnessed the war atrocities, stated: 
"If you have education the sky is unlimited, with education the sky becomes unlimited. That has taught me moving on and advancing and that's what we do...". Others talked about the appreciation of fellow humans and family as well as the present situation and life itself. One male participant who had severely suffered from poverty during the war said: "A very much hard time ... but now it is better. I appreciate this present situation that we are in."

Benevolence (67\%/80\%). This theme was composed of various aspects of unselfish and compassionate behaviour directed to family, friends, the community or other persons. As a woman who faced the atrocities during war put it: "Even sometimes I would deny myself just to make sure that people in need are taken care of." Several interviewees gained a deeper insight through their experiences, and their readiness to support other people (mainly of their in-groups) increased. That means they wanted to assist others in distress. In general, their insight and changes in behaviour referred to the importance of altruistic behaviour.

\subsubsection{Collective Growth}

About a third of the participants reflecting on their worst experience ever, emphasised changes for the Sierra Leonean society more than personal ones. As a result of collective traumatic events like the long lasting war or the outbreak of Ebola, which both affected all of the country's population, societal and political developments took place.

Social transformation $(27 \% / 20 \%)$. This theme comprises articulated societal and government-induced changes for Sierra Leone and its inhabitants due to the crises. With regard to societal developments, interviewees reported on cultural changes such as the increase of considering human rights in daily life or the enhanced tolerance between different ethnic groups. For example, one male witness of the war atrocities positively pointed out the following change in Sierra Leone: "The girl child was not educated first, parents did not have sensitisation, but it has gone round to say that what the male child can do, the female child can do too. They are giving free education." In terms of political changes, participants reported that educational and health facilities were provided. The education system changed to be free and equipped classrooms were offered. There was also a more conscious focus on hygiene (water supply), not only in health care facilities but also in the general population. One participant stated: "And now the water system is also improving." Furthermore, working salaries increased and the Sunday was declared a work-free day.

\subsection{Merging Qualitative and Quantitative Data}

To develop a comprehensive model of PTG for the Sierra Leonean population the qualitative and quantitative data was merged (see Fig. 2).

\section{Discussion}

This mixed methods study attempted to gain a thorough understanding of PTG in a collectivistic West African culture, namely a Sierra Leonean sample, who suffered from collective traumata. The quantitative findings revealed that the original factor structure of the PTGI-X (Tedeschi et al., 2017) did not apply to a Sierra Leonean population. However, qualitative findings showed themes of PTG that corresponded to the five PTG dimensions 


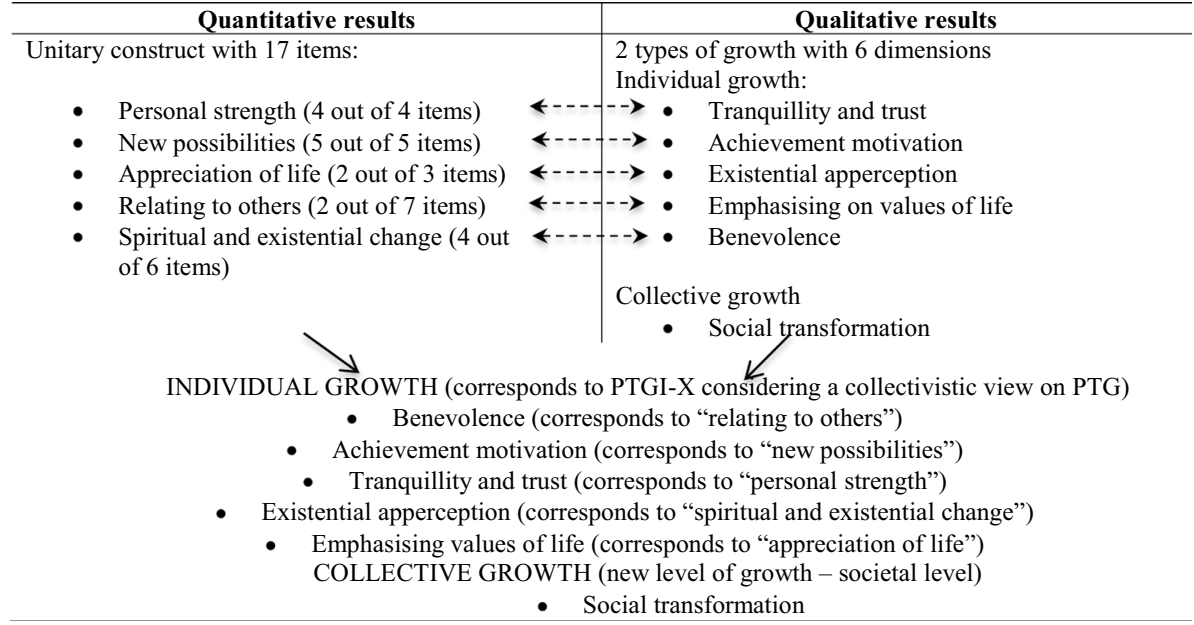

Fig. 2 PTG model for Sierra Leone

(Tedeschi et al., 2017). In this study, we grouped these themes into the domain "individual growth". In addition, we found a new domain "collective growth", which reflected societal changes. Before we discuss these findings in detail, it is important to consider that Sierra Leone is a culturally tight country, which is characterised by strong norms and low tolerance of deviant behaviour (Gelfand et al., 2011). Strong norms are applied strictly in tight societies. That means that in-group members and/or government impose sanctions on people who are not following the rules (ibid.). Tight cultures are associated with relatively greater exposure to collective trauma (Gelfand et al., 2011), and co-occur with collectivism (Triandis, 1995). Based on those facts, we used the cultural syndrome of collectivism-individualism as a framework to discuss PTG (Splevins et al., 2010), and investigated the effect of collective trauma in this specific culture.

\subsection{Quantitative Study}

Even though various scholars (e.g., Cohen et al., 1998; Taku et al., 2008) found that the PTGI should be considered as a multi-dimensional measurement, in our sample we obtained through PCA a one-factor PTG model including 17 items. The assumption that personal growth is a unitary phenomenon is not new as shown in scholarly literature (Joseph et al., 2004; Sheikh \& Marotta, 2005). Cohen et al. (1998) assumed that the unidimensionality of growth might indicate that the growth process represents a snowball effect, in which a positive change in one dimension produces a positive change in another one. Our sample reported PTG in an average amount, i.e. about $50.0 \%$ of the participants perceived positive change. No differences concerning sex were found. Vishnevsky et al. (2010) showed that differences concerning sex in favour of women emerge only after the age of 35. The lack of these differences in our study could be due to the participants' lower mean age. In contrast to previous research (e.g., Barskova \& Oesterreich, 2009; Helgeson et al., 2006; Linley \& Joseph, 2004) age was unrelated to PTG. In accordance with the finding of Helgeson et al.'s (2006) meta-analytic review of benefit finding, the elapsed time since trauma was not related to PTG. In contrast to various study findings (e.g., Helgeson et al., 2006; Park et al., 1996) religiosity was unrelated to PTG. This might be attributed 
to the fact that the vast majority of the sample stated that they are active believers, furthermore, they also consistently emphasised their confidence in God during the qualitative interviews. It might be that participants did not indicate at the PTGI-X that they experienced "spiritual-existential" change to a very great degree as a result of their crisis because they are very religious anyway (see Splevins et al., 2010). Furthermore, the starting position of the PTG model postulates that extreme events may be necessary to shatter fundamental assumptions (Janoff-Bulman, 1992) and produce more positive change than less extreme events (Tedeschi \& Calhoun, 1996). In general there is evidence that intermediate levels of symptoms were related to higher levels of growth. This curvilinear relationship between PTSD symptoms and growth was for example ascertained in Solomon and Dekel's (2007) sample with Israeli ex-prisoners of war. Based on this result, one explanation for the missing correlation between the traumatic event and growth in our sample could be that the named stressful events reached such an extremely traumatic level that the participants only experienced an average amount of growth. Another explanation for this missing correlation could be due to the fact that the core assumptions according to Janoff-Bulman (1992) represent the viewpoint of a Western individualistic society, which is reflected within the PTG model (Splevins et al., 2010). In other words, people of different cultures might have different core assumptions about the universe, life and the self (De Silva, 2006). Moreover, the core assumptions of the Sierra Leonean population might also be shaped by the multidimensional poverty that people face (Oxford Poverty and Human Development Initiative Sierra Leone, OPHI, 2019), and poor sensitisation of trauma management due to the country's limited resources for providing mental healthcare (Alemu et al., 2012). Based on the assumption that the Sierra Leonean population hold different core beliefs than cultures shaped by individualistic societies, it might be that their trauma processing could ultimately result in different PTG dimensions.

\subsection{Merging Qualitative and Quantitative Data}

By merging the qualitative and quantitative data, an outstanding result was the new domain "collective growth" with its corresponding theme "social transformation". Social transformation was again divided into two codes: "collective development" and "system development". The former code referred to improved intergroup cohesion and empathy, which was in line with "communal growth" in terms of Wlodarczyk et al. (2017). The latter was corresponding to "societal growth" (Wlodarczyk et al., 2017) and comprised positive changes in cultural values. Different authors have already concluded that people might perceive not only personal but also societal changes and benefits after collective trauma (e.g. Tedeschi, 1999; Wlodarczyk et al., 2016).

The domain "individual growth" largely reflected the PTG dimensions according to Tedeschi et al. (2017). On the one hand, the original PTG dimensions and the ones named by the Sierra Leonean participants were overlapping on the other hand our sample described additional facets of growth. De Silva's (2006) assumption that the processing of trauma is shaped by culture was clearly shown in our sample: not only the new mentioned growth dimensions were moulded by collectivistic beliefs, but also most of the overlapping dimensions. Traditionally, collectivistic cultures attach greater importance to relatedness and interdependence than to self-development (Guisinger \& Blatt, 1994; Triandis, 1995). For example the theme "tranquillity and trust" was corresponding to the PTGI-X dimension "personal strength". Our code "competence" best reflected this PTGI-X dimension (personal strength), focusing on the recognition of possessing 
personal strength. The other codes derived from our sample "peace of mind", "acceptance of destiny", and "optimism" rather referred to being in harmony with oneself and the world. The code "acceptance of destiny" was in line with the PTGI-X item no.12 "I am better able to accept the way things work out". In addition, the Sierra Leonean participants expanded this code with the code "peace of mind", which could be viewed as an advanced level of "acceptance of destiny", putting a focus on forgiving and forgetting of past events and persons involved in them. This finding is not surprising, given the fact that forgiveness has been identified as a way of coping with the effects of war in a Sierra Leonean population (Toussaint, Peddle, Cheadle, Sellu, and Luskin, 2010). In general, Lichtenfeld, Maier, Buechner, and Fernández Capo (2019) stated that forgiveness is essential for restoring relationships. According to Fincham, Jackson, and Beach (2005) forgiveness serves as an important response to a fundamental human challenge "to maintain relatedness with fellow humans in the face of being harmed by them" (p. 860). Specifically, Hook et al. (2009) focussed on the role of culture in forgiveness. The authors assumed that there is a distinct relationship between collectivism and forgiveness because social harmony is a core element of collectivistic cultures. "Collectivistic forgiveness" (p. 825) is defined as an individual's decision to forgive the offender to alleviate conflict and maintain group harmony (Hook et al., 2009). Forgiveness is preliminary decisional for individuals belonging to collectivistic cultures, and emotional - in the sense of obtaining inner peace - for individuals belonging to individualistic cultures (ibid.). Moreover, forgiveness is also based on religious demands (Hook et al., 2009) as the participants emphasised during the interviews that "God will forgive those who forgive others". Forgiveness and reconciliation were also important topics in the testimonies of female Rwandan genocide survivors (Williamson, 2014). Even though "optimism" was considered as a distinct concept of PTG by Tedeschi and Calhoun (2004) - it included neither a property of transformation nor a shift of functioning - we interpreted optimism as an outcome. In the aftermath of the devastating war and its disastrous consequences it seemed that participants attained optimism fuelling their future.

The qualitative theme "achievement motivation" is equivalent to the PTGI-X dimension "new possibilities". All items of the "new possibilities" dimension (Tedeschi et al., 2017) were included in the PTGI-X-SL. Even though Sierra Leone is a multidimensional poor country, which faces a variety of difficulties (OPHI, 2019), participants identified possibilities of taking a new and different path in life or resumed and intensified previous actions. An explanation for the participants' seizing of opportunities could be related to the domain "collective growth", which contained changes at a societal level and provided new chances and better living conditions for the people.

The theme "emphasising values of life" emerged from the qualitative data and broadened the original PTGI-X dimension "appreciation of life". In addition to the appreciation of the present moment and life in general (items no. 2 and 13 of the PTGI-X), the Sierra Leonean sample identified the appreciation of "ideals" and "fellow humans and family", which can be counted among the "universalism values" according to Schwartz et al. (2012). Universalism values comprise "tolerance" (broadminded, mature understanding) and "societal concern" (equality for all, social justice, world at peace) (ibid.). Given the fact that people tend to adapt their values to their life circumstances (Schwartz, 2011), it can be assumed that the emerging theme "emphasising values of life" of our sample was trauma-driven. The participants experienced severe personal restrictions that made them internalise societal concern as a result of war and prosecution. Schwartz and Bardi (1997) suggested that the importance of values increases when they are grounded in anxiety and their attainment is blocked. 
The PTGI-X items on the "relating to others" subscale imply an interpersonal way of expression more common in an individualistic society. For example, item no. 16 "I put more effort into my relationships" is a concept that may be differently interpreted in collectivistic cultures where relationships are very meaningful and daily practices are associated with this interconnectedness are part of "automatic" (Splevins et al., 2010). In contrast, the corresponding theme "benevolence" (identified by the Sierra Leonean sample) emphasised a collectivistic view to describe changes in their relations with other people. The participants strove to enhance the well-being of others (codes "caring actions for others" and "encouraging others due to experience") to improve the well-being of the community at large. This sincere concern for others is equivalent to collectivistic values (Prilleltensky \& Nelson, 2000). In addition, different community structures are generally in force in a Sierra Leonean context. For example, traditional healers are consulted to regulate traumatic experience. They are similar to community groups of traditional women and healers in Liberia who were set up to reactivate their traditional strategies of care for the most distressed community members (Medeiros, 2007).

As shown in the quantitative analysis of our sample, the majority of participants $(92.2 \%)$ stated that they were active believers irrespective of their religious affiliation. Not surprisingly, "existential and spiritual apperception" was also one of the most prominent themes that emerged from the qualitative data. The codes "enhanced faith" and "having confidence in God" were mentioned by almost all interviewees. These codes underlined the importance of religion and the functioning of belief systems to help people to survive and not to lose hope when having been confronted with adversities. Kroo and Nagy (2011) also reported that faith in God represented a central factor in the coping and thriving process of the Somali participants in their study, who had also experienced a long-lasting civil war. Considering the lack of social and personal resources during and after crises like a civil war or a major disease like Ebola, the only source of coping, of feeling secure or efficacious may be embedded in the faith in God, the acceptance of forces outside of their control (Kroo \& Nagy, 2011). In general, religion plays a central role in collectivistic cultures (Gelfand et al., 2011), but is of less importance in individualistic cultures (e.g., Exenberger, Kumnig, Juen, Rumpold, and Siller, 2019/Austria and Germany; Jaarsma et al., 2006/ Netherlands).

\subsection{Implication for Practice}

Two global findings regarding PTG emerge from this study that might inform practical work in the given subculture and/or in collectivistic cultures exposed to collective trauma: (1) the identification of the new PTG domain "collective growth" due to the collective trauma the majority of people have experienced and (2) the extension of the original PTG dimensions of Tedeschi et al. (2017) through a collectivistic perspective. As mentioned above, the theme of collective growth is social transformation - which in turn is divided into collective development and system development - which are closely linked to two of the themes of individual growth. Without engaging in direct attempts to induce PTG (Calhoun \& Tedeschi, 2008), the health professional's task is - if a client mentions wanting to take a new path in life - to encourage the client to seize an opportunity that has arisen through social change. This desire of the client refers to the individual growth theme achievement motivation. At this point, the health professional can cautiously point out societal changes that might have had a positive effect on personal lifestyles. In other words, a possible new perspective on crises might be highlighted: crises enable and promote social 
change and might have a positive impact on the individual (e.g., Exenberger \& Juen, 2014). Collective development, a code that is part of collective growth, is also closely interwoven with an individual growth theme, namely benevolence, which describes the desire to do something good for others. Lyubomirsky et al. (2005) showed in their experimental study that the participants reported significant benefits in subjective well-being when they performed acts of kindness. The participants' desire to live in harmony with fellow human beings and society at large again intertwines the two domains of individual and collective growth. The participants themselves have already proposed a solution to achieve this goal: Forgiveness. It is the health professional's task here to support the process of forgiveness, because forgiveness in the wake of traumatic experiences promotes personal growth, as shown in a study of Wusik et al. (2015). To sum up, if society and individuals are in a state of upheaval-it is the task of the health professional to accompany and support this collective and individual growth processes. This is best achieved, when professionals watch out carefully for possible dimensions of growth or positive change and acknowledge them.

\subsection{Limitations}

Several limitations to this study should be mentioned. According to the results of the present study, culture plays an important role in understanding the concept of PTG. To get an even deeper understanding of the concept of PTG in a Sierra Leonean context it would have been preferable to question the participants about their core beliefs (Cann et al., 2010) or basic assumptions (Janoff-Bulman, 1992). Depending on the individuals' basic assumptions, they might find different ways of rebuilding their shattered assumptions. This in turn might result in different PTG dimensions. Moreover, the participants were mainly recruited from colleges or universities. This may place some limitations on the degree to which results represent the broader population.

\subsection{Conclusion}

In conclusion, the findings of this mixed methods study clearly indicated that an individualistic measurement such as the PTGI-X falls short of the examination of growth dimensions in non-Western cultures, specifically in a Sierra Leonean context. These findings emphasise that culture strongly influences the processing of a traumatic experience, which has a major impact on practitioners. For example, Western practitioners who belong to another cultural background than their clients cannot just apply Western therapy and counselling. One needs to be aware of the fact that cultures provide many alternative pathways to healing and integration of stressful experiences (Marsella, 2010). A broader definition of PTG might foster the integration of different cultural and collective manifestations that emerge from highly stressful events. In addition, if the stressor is perceived as a collective threat, then a cooperative problem-solving process starts, since people do not only perceive personal but also communal and societal changes and benefits (Wlodarczyk et al., 2016). Finally, a cross-cultural version of a PTG measurement should be (1) broadened as there are cultural differences in the PTG experiences between individuals from individualistic and collectivistic cultures (Splevins et al., 2010), and (2) consequently it should be divided into personal, communal and societal growth (Wlodarczyk et al., 2017).

Given that Sierra Leone is a tight and collectivistic country that has experienced collective trauma, the role of PTG is particularly evident in the interplay between individual 
and collective growth. Individual growth is mainly shaped by collectivistic characteristics (e.g., benevolence), although growth dimensions that correspond more to an individualistic culture come to the fore (e.g. competence).

Acknowledgements We would like to express our sincere thanks to Assoc.-Prof. Dr. Stefan Höfer (Medical University of Innsbruck, Austria, Department of Medical Psychology), who tirelessly assisted us in improving this manuscript with his scientific and human expertise.

Funding Open access funding provided by University of Innsbruck and Medical University of Innsbruck. No funding was provided for this study.

Availability of data and material Data is not available for online access, however readers who wish to gain access to the data can write to the first author Silvia Exenberger at silvia.exenberger-vanham@i-med.ac.at for their requests, which would be subject to ethical approval.

\section{Declarations}

Conflict of interest No potential conflict of interest was reported by the authors.

Ethical approval All procedures performed in studies involving human participants were in accordance with the ethical standards of the institutional and/or national research committee and with the 1964 Helsinki declaration and its later amendments or comparable ethical standards. Ethics approval was gained by the Review Board of the ethic committee of the Freetown Teachers College, Kossoh Town.

Informed consent Written and verbal consents were obtained from all individual participants included in the study.

Open Access This article is licensed under a Creative Commons Attribution 4.0 International License, which permits use, sharing, adaptation, distribution and reproduction in any medium or format, as long as you give appropriate credit to the original author(s) and the source, provide a link to the Creative Commons licence, and indicate if changes were made. The images or other third party material in this article are included in the article's Creative Commons licence, unless indicated otherwise in a credit line to the material. If material is not included in the article's Creative Commons licence and your intended use is not permitted by statutory regulation or exceeds the permitted use, you will need to obtain permission directly from the copyright holder. To view a copy of this licence, visit http://creativecommons.org/licenses/by/4.0/.

\section{References}

Alemu, W., Funk, M., Gakurah, T., Bash-Taqi, D., Bruni, A., Sinclair, J., Kobie, A., Muana, A., Samai M,, Eaton, J. (2012). WHO Profile on mental health in development (WHO proMIND): Sierra Leone. Geneva: World Health Organization. https://www.who.int/mental_health/policy/country/sierra_leone_ country_summary_2012.pdf. Accessed 20 November 2020.

American Psychiatric Association. (2013). Diagnostic and Statistical Manual of Mental Disorders (5th ed.). Author.

American Psychological Association (2017). Ethical principles of psychologists and code of conduct. https://www.apa.org/ethics/code/ethics-code-2017.pdf. Accessed 23 March 2020.

Arbuckle, J. L. (2014). Amos 23.0 User's Guide. Chicago: IBM SPSS.

Barskova, T., \& Oesterreich, R. (2009). Post-traumatic growth in people living with a serious medical condition and its relations to physical and mental health: A systematic review. Disability and Rehabilitation, 31(21), 1709-1733. https://doi.org/10.1080/09638280902738441

Bellows, J., \& Miguel, E. (2009). War and local collective action in Sierra Leone. Journal of Public Economics, 93(11-12), 1144-1157. https://doi.org/10.1016/j.jpubeco.2009.07.012

Braun, V., \& Clarke, V. (2006). Using thematic analysis in psychology. Qualitative Research in Psychology, 3(2), 77-101. https://doi.org/10.1191/1478088706qp063oa 
Brown, T. A. (2015). Confirmatory Factor Analysis for Applied Research (2nd ed.). The Guilford Press.

Buehner, M. (2006). Einführung in die Test- und Fragebogenkonstruktion (2. Aufl.). [Introduction to the test construction and questionnaire construction (2nd ed.]. München: Pearson Studium.

Bundesgesetz über die Organisation der Universitäten und ihre Studien (Universitätsgesetz 2002 - UG), as amended on 19 June 2018. [Federal Act on the Organisation of Universities and their Studies (university act 2002), as amended on 19 June 2018]. https://www.ris.bka.gv.at/GeltendeFassung/Bundesnorm en/20002128/UG\%2c\%20Fassung\%20vom\%2019.06.2018.pdf. Accessed 23 March 2020.

Bundesgesetz über Krankenanstalten und Kuranstalten - KAKuG). (1957/amended 2016). Hospitals and Health Resorts Act. https://www.ris.bka.gv.at/eli/bgbl/I/2016/3/20160223. Accessed 23 March 2020.

Calhoun, L. G., \& Tedeschi, R. G. (2006). The foundations of posttraumatic growth: An expanded framework. In L. G. Calhoun \& R. G. Tedeschi (Eds.), Handbook of posttraumatic growth: Research \& practice (pp. 3-23). Lawrence Erlbaum Associates Publishers.

Calhoun, L. G., \& Tedeschi, R. G. (2008). The paradox of struggling with trauma: Guidelines for practice and directions for research. In S. Joseph, \& P. A. Linley (Eds.), Trauma, recovery and growth. Positive psychological perspectives on posttraumatic stress (pp. 325-38). Hoboken, NJ,: John Wiley \& Sons, Inc.

Cann, A., Calhoun, L. G., Tedeschi, R. G., Kilmer, R. P., Gil-Rivas, V., Vishnevsky, T., \& Danhauer, S. C. (2010). The Core Beliefs Inventory: A brief measure of disruption in the assumptive world. Anxiety, Stress, \& Coping, 23(1), 19-34. https://doi.org/10.1080/10615800802573013

Cohen, L. H., Cimbolic, K., Armeli, S. R., \& Hettler, T. R. (1998). Quantitative assessment of thriving. Journal of Social Issues, 54(2), 323-335.

IBM Corp. (2016). IBM SPSS Statistics for Windows, Version 24.0. Armonk, NY: IBM Corp.

Creswell, J. W., \& Plano Clark, V. L. (2011). Designing and conducting mixed methods research (2nd ed.). Sage.

De Silva, P. (2006). The tsunami and its aftermath in Sri Lanka: Explorations of a Buddhist perspective. International Review of Psychiatry, 18(3), 281-287. https://doi.org/10.1080/09540260600658270

Exenberger, S., \& Juen, B. (2014). Well-being, resilience and quality of life from children's perspectives: a contextualized approach. Dordrecht, Heidelberg: Springer Briefs.

Exenberger, S., Kumnig, M., Juen, B., Rumpold, G., \& Siller, H. (2019). Dimensions of posttraumatic growth in a German-speaking Sample Using Mixed Methods. European Journal of Psychotraumatology. 10(1). https://doi.org/10.1080/20008198.2019.1701258

Gelfand, M. J., Raver, J. L., Nishii, L., Leslie, L. M., Lun, J., Lim, B. C., Duan, L., Almaliach, A., Ang, A., Arnadottir, J., Aycan, Z., Boehnke, K., Boski, P., Cabecinhas, R., Chan, D., Chhokar, J., D’Amato, A., Ferrer, M., Fischlmayr, I. C., Fischer, R., Fülöp, M., Georgas, J., Kashima, E. S., Kashima, Y., Kim, K., Lempereur, A., Marquez, P., Othman, R., Overlaet, B., Panagiotopoulou, P., Peltzer, K., PerezFlorizno, L. R., Ponomarenko, L., Realo, A., Schei, V., Schmitt, M., Smith, P. B., Soomro, N., Szabo, E., Taveesin, N., Toyama, M., Van de Vliert, E., Vohra, N., Ward, C., \& Yamaguchi, S. (2011). Differences between tight and loose cultures: A 33-nation study. Science, 332, 1100-1104.

Guisinger, S., \& Blatt, S. J. (1994). Individuality and relatedness. Evolution of a fundamental dialectic. American Psychologist, 49(2), 104-111.

Hanlon, J. (2005). Is the international community helping to recreate the pre-conditions for war in Sierra Leone? WIDER Research Paper, No. 2005/50. The United Nations University World Institute for Development Economics Research (UNU-WIDER), Helsinki. http://hdl.handle.net/10419/63426. Accessed 9 March 2019.

Heidarzadeh, M., Rassouli, M., Brant, J. M., Mohammadi-Shahbolaghi, F., \& Alavi-Majd, H. (2017). Dimensions of posttraumatic growth in patients with cancer: A mixed method study. Cancer Nursing. https://doi.org/10.1097/NCC.0000000000000537

Helgeson, V. S., Reynolds, K. A., \& Tomich, P. L. (2006). A meta-analytic review of benefit finding and growth. Journal of Consulting and Clinical Psychology, 74(5), 797-816. https://doi.org/10.1037/0022006X.74.5.797

Hirschberger, G. (2018). Collective trauma and the social construction of meaning. Frontiers in Psychology. https://doi.org/10.3389/fpsyg.2018.01441

Ho, S. M., Chan, C. L., \& Ho, R. T. (2004). Posttraumatic growth in Chinese cancer survivors. PsychoOncology, 13(6), 377-389. https://doi.org/10.1002/pon.758

Hofstede, G. (2020). Country comparison: Sierra Leone. https://www.hofstede-insights.com/country-compa rison/sierra-leone/. Accessed 9 March 2020.

Hook, J. N., Worthington, E. L., \& Utsey, S. O. (2009). Collectivism, forgiveness, and social harmony. The Counselling Psychologist, 37(6), 821-847. https://doi.org/10.1177/0011000008326546 
Hu, L., \& Bentler, P. M. (1998). Fit indices in covariance structure modelling: Sensitivity to underparameterized model misspecification. Psychological Methods, 3(4), 424-453. https://doi.org/10.1037/1082989X.3.4.424

Hu, L., \& Bentler, P. M. (1999). Cutoff criteria for fit indexes in covariance structure analysis: Conventional criteria versus new alternatives. Structural Equation Modeling, 6(1), 1-55. https://doi.org/10.1080/ 10705519909540118

Hussain, D., \& Bhushan, B. (2013). Posttraumatic growth experiences among Tibetan refugees: A qualitative investigation. Qualitative Research in Psychology, 10(2), 204-216. https://doi.org/10.1080/14780 887.2011.616623

Jaarsma, T. A., Pool, G., Sanderman, R., \& Ranchor, A. V. (2006). Psychometric properties of the Dutch version of the posttraumatic growth inventory among cancer patients. Psycho-Oncology, 15(10), 911920. https://doi.org/10.1002/pon.1026

Janoff-Bulman, R. (1992). Shattered assumptions: Towards a new psychology of trauma. Free Press.

Joseph, S., Linley, P. A., \& Harris, G. J. (2004). Understanding positive change following trauma and adversity: Structural clarification. Journal of Loss and Trauma, 10(1), 83-96. https://doi.org/10.1080/15325 020490890741

Kaiser, H. F. (1960). The application of electronic computers to factoranalysis.Educational and Psychological Measurement, 20,141-151. https://doi.org/10.1177/001316446002000116

Kilic, C., Magruder, K. M., \& Koryürek, M. M. (2015). Does trauma type relate to posttraumatic growth after war? A pilot study of young Iraqi war survivors living in Turkey. Transcultural Psychiatry, 53(1), 110-123. https://doi.org/10.1177/1363461515612963

Kroo, A., \& Nagy, H. (2011). Posttraumatic growth among traumatized Somali refugees in Hungary. Journal of Loss and Trauma, 16(5), 440-458. https://doi.org/10.1080/15325024.2011.575705

Lee, E., Kim S., \& Enright, R. D. (2017). Beyond grief and survival: Posttraumatic growth through immediate family suicide loss in South Korea. OMEGA - Journal of Death and Dying O(0), 1-22. https://doi. org/10.1177/0030222817724700

Lev-Wiesel, R., \& Amir, M. (2003). Posttraumatic growth among Holocaust child survivors. Journal of Loss and Trauma: International Perspectives on Stress \& Coping, 8(4), 229-237. https://doi.org/10.1080/ 15325020305884

Linley, P. A., \& Joseph, S. (2004). Positive change following trauma and adversity: A review. Journal of Traumatic Stress, 17(1), 11-21.

Lyubomirsky, S., Sheldon, K. M., \& Schkade, D. (2005). Pursuing happiness: The architecture of sustainable change. Review of General Psychology, 9(2), 111-131. https://doi.org/10.1037/1089-2680.9.2.111

MacCallum, R. C., Widaman, K. F., Zhang, S., \& Hong, S. (1999). Sample size in factor analysis. Psychological Methods, 4, 84-99.

Maercker, A., \& Langner, R. (2001). Persönliche Reifung (Personal Growth) durch Belastungen und Traumata: Ein Vergleich zweier Frageboegen zur Erfassung selbst- wahrgenommener Reifung nach traumatischen Ereignissen. Diagnostica, 47, 153-162.

Marsella, A. J. (2010). Ethnocultural aspects of PTSD: An overview of concepts, issues, and treatments. Traumatology, 16(4), 17-26. https://doi.org/10.1177/1534765610388062

Medeiros, E. (2007). Integrating mental health into post-conflict rehabilitation-The case of Sierra Leonean and Liberian 'Child Soldiers.' Journal of Health Psychology, 12(3), 498-504. https://doi.org/10.1177/ 1359105307076236

Morris, B. A., Shakespeare-Finch, J., Rieck, M., \& Newbery, J. (2005). Multidimensional nature of posttraumatic growth in an Australian population. Journal of Traumatic Stress, 18(5), 575-585. https://doi. org/10.1002/jts.20067

Norris, F. H., Friedman, M. J., Watson, P. J., Byrne, C. M., Diaz, E., \& Kaniasty, K. (2002). 60.000 disaster victims speak: Part I. An empirical review of the empirical literature, 1981-2001. Psychiatry, 65(3), 207-239.

O'Connor, B. P. (2000). SPSS and SAS programs for determining the number of components using parallel analysis and Velicer's MAP test. Behavior Research Methods, Instruments, \& Computers, 32(3), 396-402.

Oxford Poverty and Human Development Initiative, OPHI (2019). Sierra Leone Multidimensional Poverty Index 2019. UNDP Sierra Leone. Retrieved from https://ophi.org.uk/wp-content/uploads/Sierra_ Leone_MPI_2019_final.pdf

Páez, D., Basabe, N., Ubillos, S., \& González-Castro, J. L. (2007). Social sharing, participation in demonstrations, emotional climate, and coping with collective violence after the March 11th Madrid bombings. Journal of Social Issues, 63(2), 323-337.

Pals, J. L., \& McAdams, D. P. (2004). The transformed self: A narrative understanding of posttraumatic growth. Psychological Inquiry, 15(1), 65-69. 
Park, C. L., Cohen, L. H., \& Murch, R. L. (1996). Assessment and prediction of stress-related growth. Journal of Personality, 64(1), 72-105.

Powell, S., Rosner, R., Butollo, W., Tedeschi, R. G., \& Calhoun, L. G. (2003). Posttraumatic growth after war: A study with former refugees and displaced people in Sarajevo. Journal of Clinical Psychology, 59(1), 71-83. https://doi.org/10.1002/jclp.10117

Prilleltensky, I., \& Nelson, G. (2000). Promoting child and family wellness: Priorities for psychological and social interventions. Journal of Community \& Applied Social Psychology, 10(2), 85-105.

Salo, J. A., Qouta, S., \& Punamäki, R. (2005). Adult attachment, posttraumatic growth and negative emotions among former political prisoners. Anxiety, Stress, and Coping, 18(4), 361-378. https://doi.org/10. $1080 / 10615800500289524$

Schwartz, S. H. (2011). Studying values: Personal adventure, future directions. Journal of Cross-Cultural Psychology, 42(2), 307-319. https://doi.org/10.1177/0022022110396925

Schwartz, S., \& Bardi, A. (1997). Influences of adaptation to communist rule on value priorities in Eastern Europe. Political Psychology, 18(2), 385-410. https://doi.org/10.1111/0162-895X.00062

Schwartz, S. H., Cieciuch, J., Vecchione, M., Davidov, E., Fischer, R., Beierlein, C., Ramos, A., Verkasalo, M., Lönnqvist, J.-E., Demirutku, K., Dirilen-Gumus, O., \& Konty, M. (2012). Refining the theory of basic individual values. Journal of Personality and Social Psychology, 103(4), 663-688. https://doi.org/10.1037/a0029393

Shakespeare-Finch, J., \& Copping, A. (2006). A Grounded Theory approach to understanding cultural differences in posttraumatic growth. Journal of Loss and Trauma, 11(5), 355-371. https://doi.org/ $10.1080 / 15325020600671949$

Sheikh, A. I., \& Marotta, S. A. (2005). A Cross-validation study of the Posttraumatic Growth Inventory. Measurement and Evaluation in Counseling and Development, 38(2), 66-77. https://doi.org/ 10.1080/07481756.2005.11909769

Solomon, Z., \& Dekel, R. (2007). Posttraumatic stress disorder and posttraumatic growth among Israeli ex-POWs. Journal of Traumatic Stress, 20(3), 303-312. https://doi.org/10.1002/jts.20216

Splevins, K., Cohen, K., Bowley, J., \& Joseph, S. (2010). Theories of posttraumatic growth: Cross-cultural perspectives. Journal of Loss and Trauma: International Perspectives on Stress \& Coping, 15(3), 259-277. https://doi.org/10.1080/15325020903382111

Taku, K., Cann, A., Calhoun, L. G., \& Tedeschi, R. G. (2008). The factor structure of the posttraumatic growth inventory: A comparison fo five models using confirmatory factor analysis. Journal of Traumatic Stress, 21(2), 158-164. https://doi.org/10.1002/jts.20305

Tashiro, T., \& Frazier, P. (2003). "I'll never be in a relationship like that again": Personal growth following romantic relationship breakups. Personal Relationships, 10(1), 113-128. https://doi.org/10. 1111/1475-6811.00039

Tedeschi, R. G. (1999). Violence transformed. Posttraumatic growth in survivors and their societies. Aggression and Violent Behavior, 4(3), 319-341.

Tedeschi, R. G., \& Calhoun, L. G. (1995). Trauma \& transformation: Growing in the aftermath of suffering. Sage Publications Inc.

Tedeschi, R. G., \& Calhoun, L. G. (1996). The Posttraumatic Growth Inventory: Measuring the positive legacy of trauma. Journal of Traumatic Stress, 9(3), 455-472. https://doi.org/10.1002/jts.24900 90305

Tedeschi, R. G., \& Calhoun, L. G. (2004). Posttraumatic growth: Conceptual foundations and empirical evidence. Psychological Inquiry, 15(1), 1-18.

Tedeschi, R. G., Cann, A., Taku, K., Senol-Durak, E., \& Calhoun, L. G. (2017). The Posttraumatic Growth Inventory: A Revision Integrating Existential and Spiritual Change. Journal of Traumatic Stress, 30(1), 11-18. https://doi.org/10.1002/jts.22155

Toussaint, L. L., Peddle, N., Cheadle, A., Sellu, A., \& Luskin, F. (2010). Striving for peace through forgiveness in Sierra Leone. In A. S. Ka- layjian \& D. Eugene (Eds.). Mass trauma and emotional healing around the world: Rituals and practices for resilience and meaning-making (Vol. 2, pp. 251-267). Santa Barbara, CA: ABC-CLIO, LLC.

Triandis, H. C. (1995). Individualism \& collectivism. Westview Press.

United Nations, (1993). Human Development Report 1993. United Nations Development Program. New York: Oxford University Press.

United Nations Development Programme (2019). Inequalities in human development in the $21^{\text {st }}$ century - Sierra Leone. http://hdr.undp.org/sites/all/themes/hdr_theme/country-notes/SLE.pdf. Accessed 23 March 2020.

Vázquez, C., Pérez-Sales, P., \& Hervás, G. (2008). Positive effects of terrorism and posttraumatic growth: An individual and community per- spective. In S. Joseph \& P. A. Linley (Eds.), Trauma, recovery, and growth: Positive psychological perspectives on posttraumatic stress (pp. 63-91). Wiley. 
Vishnevsky, T., Cann, A., Calhoun, L. G., Tedeschi, R. G., \& Demakis, G. J. (2010). Gender differences in self-reported posttraumatic growth: A meta-analysis. Psychology of Women Quarterly, 34(1), 110-120. https://doi.org/10.1111/j.1471-6402.2009.01546.x

Walker-Williams, H. J., van Eeden, C., \& van der Merwe, K. (2012). The Prevalence of Coping Behaviour, Posttraumatic Growth and Psychological Well-Being in Women who Experienced Childhood Sexual Abuse. Journal of Psychology in Africa, 22(4), 617-626. https://doi.org/10.1080/14330237. 2012.10820576

Weiss, T., \& Berger, R. (2006). Reliabiliy and validity of a Spanish version of the Posttraumatic Growth Inventory. Research on Social Work Practice, 16(2), 191-199. https://doi.org/10.1177/1049731505 281374

World Health Organization (WHO, 2016). Ebola situation report - Sierra Leone. http://apps.who.int/ ebola/current-situation/ebola-situation-report-16-march-2016. Accessed 9 March 2020.

Williamson, C. (2014). Towards a theory of collective posttraumatic growth in Rwanda: The pursuit of agency and communion. Traumatology: An International Journal, 20(2), 91-102. https://doi.org/10. $1037 / \mathrm{h} 0099393$

Witzel, A. (2000). Das problemzentrierte Interview. [The problem-centered interview]. Forum Qualitative Sozialforschung/Forum: Qualitative Social Research 1(1). http://www.qualitative-research.net/index. php/fqs/rt/printerFriendly/1132/2519. Accessed 23 March 2020.

Wlodarczyk, A., Basabe, N., Páez, D., Reyes, C., Villagrán, L., Madariaga, C., \& Palacio, J. (2016). Communal coping and posttraumatic growth in a context of natural disasters in Spain, Chile, and Colombia. Cross-Cultural Research, 50(4), 325-355. https://doi.org/10.1177/1069397116663857

Wlodarczyk, A., Basabe, N., Páez, D., Villagrán, L., \& Reyes, C. (2017). Individual and collective posttraumatic growth in victims of natural disasters: A multidimensional perspective. Journal of Loss and Trauma, 22(5), 371-384. https://doi.org/10.1080/15325024.2017.1297657

Wusik, M. F., Smith, A. J., Jones, R. T., \& Hughes, M. (2015). Dynamics among posttraumatic stress symptoms, forgiveness for the perpetrator, and posttraumatic growth following collective trauma. Journal of Community Psychology, 43(4), 389-394. https://doi.org/10.1002/jcop.21686

Publisher's Note Springer Nature remains neutral with regard to jurisdictional claims in published maps and institutional affiliations. 